\title{
MELT SHEAR VISCOSITY OF ORIGINAL AND RECYCLED PET IN WIDE RANGE SHEAR RATE
}

\begin{abstract}
Among the plastic materials, the PET is the most often used one. Collecting of the material to be recycled is partially solved. This way we have great quantity of regrinded PET. During the regrinding the structure of molecules changes, and these properties can be measured by rheological methods. Polymer melts are-newtonian fluids and the flow curves of the materials can be used to characterize the molecular weight and the molecular weight distribution. This research is focused on the characterization of original and regrinded PET materials. Inherent viscosities (IV) were determined to characterize the materials. Flow curves of pure and blended materials were measured at different temperatures.

Keywords: PET, regrind, oscillation rheology, capillary viscosity
\end{abstract}

\section{Introduction}

Nowadays polyethylene terephthalate (PET) is one of the most common plastics, because of its widespread use. There are certain places where recycled PET is already used and produced. Our goal is to increase the quantity of the recycled PET. From the recycled materials the new bottles, products can be made. This requires a development path and a more sophisticated technology since it is not easy to determine for once used bottle what was stored in it, how it was used previously [1]. PET is a hygroscopic thermoplastic polymer, therefore drying process is very important, since it affects the rheological properties of the material, the subsequent processing, and the product characteristics [2]. The rheological analysis mentioned in this paper is of polyethylene terephthalate (PET) base material, in which a specific raw material - a melt viscosity of structural, elastic and viscoelastic behavior was investigated. The study was carried out by ARES-G2 type oscillational rheometer, and Goettfert Rheograph 25 capillary rheometer with which the material was examined at low and high shear rate. The original granule wereanalyzed between $270-290{ }^{\circ} \mathrm{C}$. Then, the original raw material was processed $\mathrm{BT}$ injection molding machine and then it was granulated again. There was a full investigation at the same temperatures. The measuring values are presented on diagrams and from these the conclusions were drawn.

\section{Material}

RAMAPET N180 is a general purpose, non-reheat PET resin for bottles, film, thermoformed containers and other transparent applications. It has good optical properties, the mechanical properties are representative for PET resin. The PET is hygroscopic in little extent, and since moisture adversely affects the IV during the melt processing of the polymer, it must be dried prior to molding. Undried PET pellets can contain up to $0.2 \%$ (2000 ppm) of moisture. After drying, the moisture content is typically below $50 \mathrm{ppm}$ [3].

PET has good surface hardness, stiffness, and dimensional stability. It has good gas barrier properties and good chemical resistance except for alkaline materials (which hydrolyze it). Its structure varies from amorphous to fairly high crystalline; it can be highly transparent and colorless but thicker sections are usually opaque and off - white. The PET material is heat - resistant until $180{ }^{\circ} \mathrm{C}$, it does not decrease in strength, its melting temperature is around $260{ }^{\circ} \mathrm{C}$. Above $250{ }^{\circ} \mathrm{C}$ the crystallite section is continuously disappearing, so the melting process of the material could be observed. Usually, the material is processed in the molten state, so it is worth to study the rheological properties only above this temperature [4]. The measurements were performed at $270{ }^{\circ} \mathrm{C}, 280{ }^{\circ} \mathrm{C}$ and $290{ }^{\circ} \mathrm{C}$.

\footnotetext{
* Attila Bata, Gergely Toth, Karoly Belina

Department of Materials Technology, GAMF Faculty of Mechanical Engineering and IT, Pallas Athena University, Hungary bata.attila@gamf.kefo.hu
} 


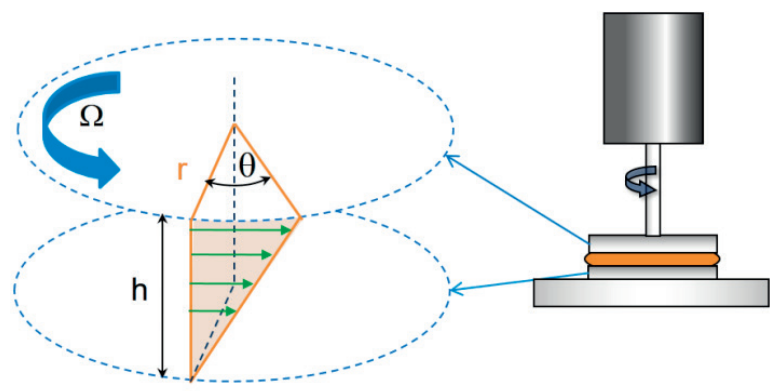

Figure 1 Rotation viscometry CMT conceptual layout and marking system [5]

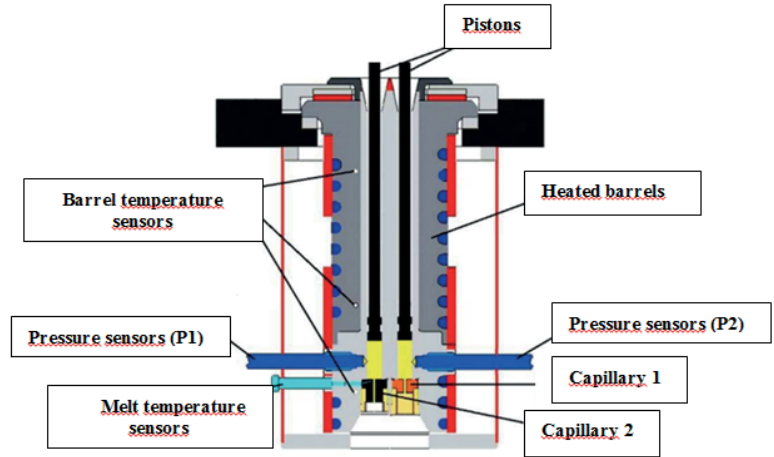

Figure 2 Capillary rheometer conceptual layout [7]

\section{Method}

\subsection{The rotational viscometry}

Our measurements were carried out by a shear viscosity investigation method; that means a low range of shear rate and temperature steps near the processing temperature. This was the reason why the rotational viscometry was measured in the low shear rate range $\left(0.05-20^{1} / \mathrm{s}\right)$. With the rotational viscometry we could measure torsion flow in a polymer melt between parallel plates. The measuring technique conceptual layout is shown in Figure 1. The CMT means combined motor and transducer concept [5].

From the marking system the stress, deformation and deformation rate components can be calculated with the equations described below:

$$
\begin{aligned}
\sigma & =\frac{2}{\pi r^{3}} \times M \\
\gamma & =\frac{r}{h} \times \theta \\
\dot{\gamma} & =\frac{r}{h} \times \Omega
\end{aligned}
$$

where $\mathbf{r}$ is the circular plate radius; $\mathbf{h}$ is the gap between the plates; $\boldsymbol{\theta}$ is the driving engine rotation ( $\mathrm{rad}$ ); $\boldsymbol{\Omega}$ is the driving engine angular speed ( $\mathrm{rad} / \mathrm{s})$ and $\mathbf{M}$ is the torque $(\mu \mathrm{Nm})$ [5]

The stress and deformation rate can be calculated from Equations (1) to (3) and the shear viscosity can be defined. It is a frequent measuring technique to determine shear viscosity for small molecular liquids, or oils and thermoplastics at low shear rate. ARES G2 is equipped with Forced Convention Oven (FCO). With this accessory materials can be examined at higher temperature (to $600{ }^{\circ} \mathrm{C}$ ) and the degradation process can be monitored. For our testing TA Ares G2 type rotation viscometer was used with cone - plate geometry in $25 \mathrm{~mm}$ diameter. The trim gap was $0.09 \mathrm{~mm}$, while the measuring gap was $0.04 \mathrm{~mm}$. SMT (Separate motor and transducer) layout was used. In this type of rotation viscometer, the drive engine and the transducer are separated [6].

\subsection{The capillary rheometry}

The capillary rheometer is a measuring device in which the shear viscosity of thermoplastics can be measured. The shear rate ranges were between 100 and 10000 1/s near to the processing temperature [7]. The Goettfert Rheograph 25 capillary rheometer was used for the measurements. The measuring method is based on continuous melt flow in known geometry capillary (dies), while the pressure drops is measured between the capillary inlet side and the atmospheric pressure (Figure 2).

The variable parameters were the barrel temperature and the piston speed (which means the deformation rate). In this case, the shear viscosity depends on temperature and deformation (shear) rate. In our tests, the shear rate was changed between $100-10.000^{1} / \mathrm{s}$ and the barrel temperatures were changed in three steps around processing temperature, that is for the material of the supplier recommended, at $270-290{ }^{\circ} \mathrm{C}$. The measuring method used two other geometry capillaries because of the entrance and exit effects (pressure drop). With this equipment in one step the Bagley correction can be done, which corrects the pressure drop and gives the real shear viscosity [8]

\section{Results}

\subsection{The rotational viscometry}

The viscosity curves were determined in function of the shear rate. The measurements were performed with original material and with recycled material. The viscosity of the original material is shown in Figure 3 at different temperatures.

The curves measured at different temperatures are not the same. It can be observed that the viscosity is the highest at $270{ }^{\circ} \mathrm{C}$. The higher is the temperature, the lower is the viscosity. From the differences of the curves, the transformation of the molecular structure can be determined. The viscosity of the recycled materials is shown in Figure 4. 


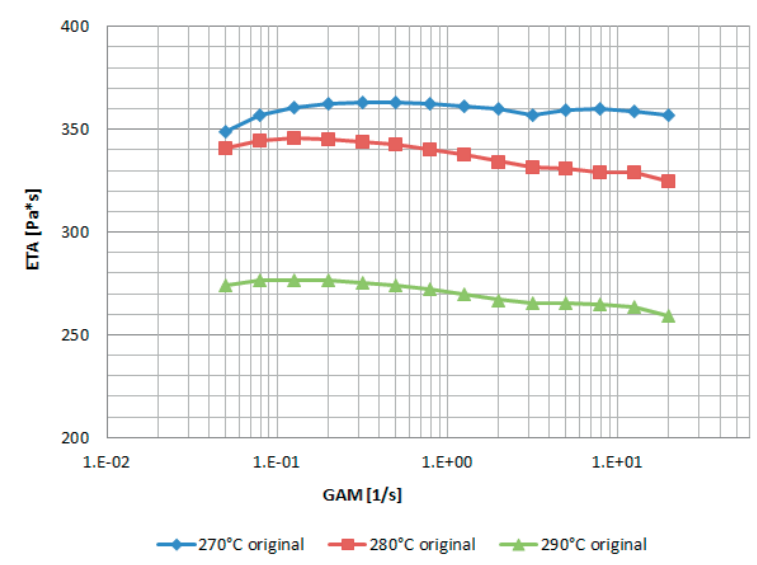

Figure 3 Shear viscosity curves of original PET

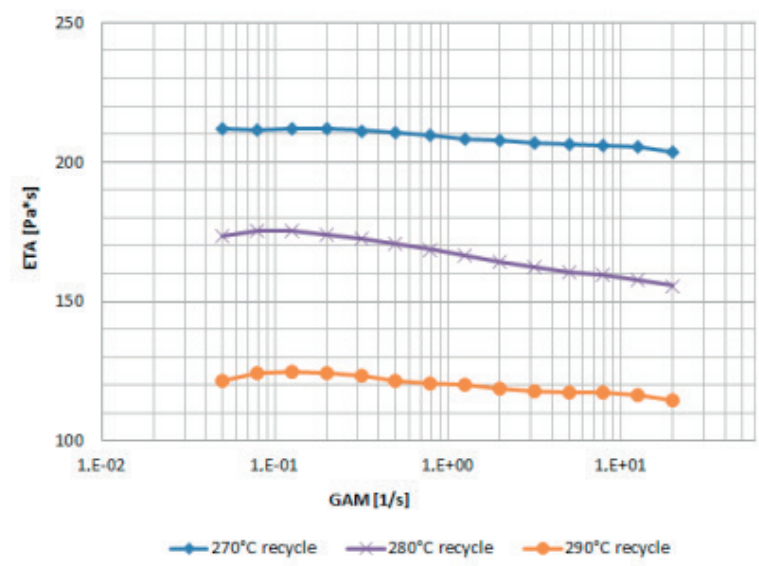

Figure 4 Shear viscosity curves of recycled PET

The recycled material shows the same tendency (Figure 4). Increasing the temperature the viscosity decreases. During the recycling and grinding processes, the molecules in the materials can easily degrade. This is caused by the rising thermal and mechanical strain during the processes. The degradation makes the molecular weight lower, so the molecular density dispersion widens. The polymer with shorter chains can move easier. Above the glass transition temperature the segments of the polymer move increasingly. The viscosities of the original and recycled materials are shown in Figure 5.

In each diagram the viscosity curves show a tipical form (Figure 5). In the curves of newtonian fluids it could be recognised that the curves are almost linear and do not depend on the shear rate. In our measurements, the viscosity curves approach the horizontal line, but they decrease within a small range. It was confirmed that these materials behave like non newtonian fluids. At a constant temperature, the difference between the original and the recycled materials approaches $150 \mathrm{~Pa}^{*} \mathrm{~s}$. The impact of the recycling is the continously decreasing molecular weight. The lower molecular weight means easier molecular movement.

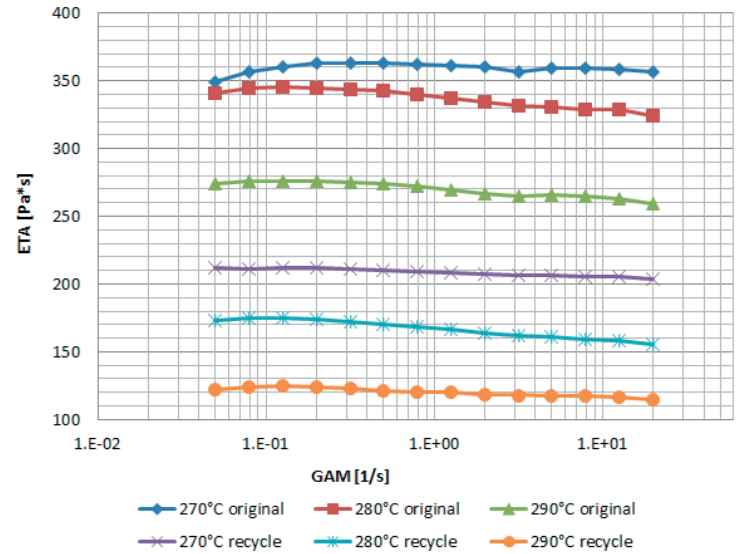

Figure 5 Shear viscosity curves of original and recycled PET

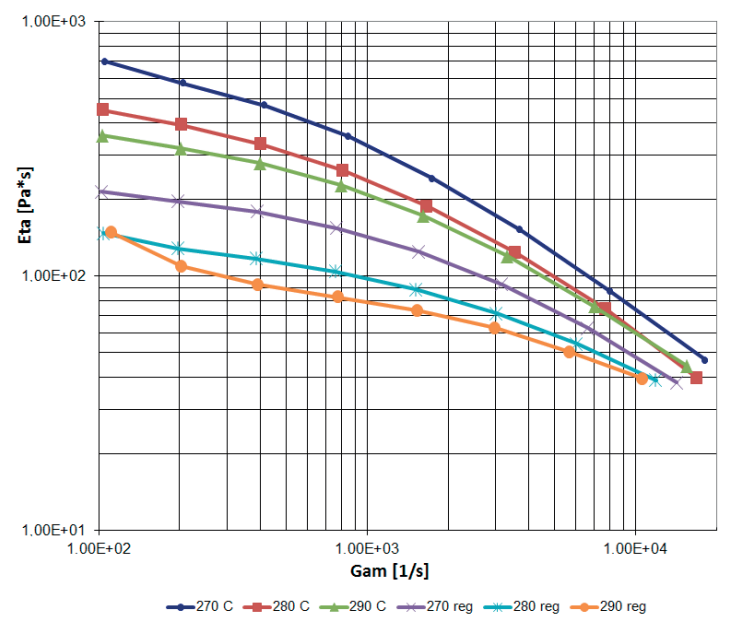

Figure 6 Shear viscosity curves of original and recycled PET

\subsection{The capillary rheometer}

The measurements were performed with original material and with recycled material. The viscosities of the original and recycled materials are shown in Figure 6.

Comparing the data to the $270{ }^{\circ} \mathrm{C}$ viscosity curve in the lower shear range: There is a $\sim 30-35 \%$ reduction at $280{ }^{\circ} \mathrm{C}$, and at $290{ }^{\circ} \mathrm{C}$ we can see a $40-50 \%$ reduction. As we approach the larger shear ranges (10000-18000 $1 / \mathrm{s})$ the differences are reduced: at $280{ }^{\circ} \mathrm{C} \sim 15-18 \%$, while at $290{ }^{\circ} \mathrm{C} \sim 7-3 \%$. In the initial shear speed range, the recycled material shows a $70 \%$ reduction at $270{ }^{\circ} \mathrm{C}$, while in the higher shear range this value shows a $15 \%-30 \%$ reduction. We could observe the following viscosity reductions in the results: at $280{ }^{\circ} \mathrm{C}, \sim 65 \%$ and at $290{ }^{\circ} \mathrm{C} \sim 50 \%$. Although the initial viscosity values at $290{ }^{\circ} \mathrm{C}$ show a different tendency compared to the curve we measured at the previous two temperatures, this can be attributed to a measurement error with a great certainty. From these values we can conclude that we have to consider the viscosity change of the material during the recycling, 
because with such a degree of deviation we could assume that the material will not be able to withstand the requirements, which are set by design.

\section{Conclusion}

In our investigation one type of material was measured, but at different temperatures and in different conditions. An original and a recycled material were examined. The measurements were performed by an ARES G2 rotational rheometer and a Goettfert Rheograph 25 capillary rheometer at $270{ }^{\circ} \mathrm{C}$, at $280{ }^{\circ} \mathrm{C}$ and at $290{ }^{\circ} \mathrm{C}$. The shear rate was changed from 0.05 to $201 / \mathrm{s}$ and $100-10000^{1} / \mathrm{s}$. It was determined that the viscosity of the recycled material is lower than the value of the original material at each temperature. The molecules of the recycled material were supposed to shorten during the grinding process. If the temperature increases, the shear viscosity decreases, but there was no linear correlation between these two variables. The structure viscous behavior of the polymer melt was revealed. This area offers lot of possibilities for further research, so we intend to continue investigations.

\section{Acknowledgement}

This research is supported by the EFOP-3.6.1-16-2016-00014 project. The Project is supported by the Hungarian Government

\section{References}

[1] RONKAY, F.: Physical Recycling of the Material of PET Bottles (in Hungarian). PhD Thesis, Budapest University of Technology and Economics, 2006

[2] CZVIKOVSZKY, T., NAGY, P., GAAL, J.: The basics of polymer technology (in Hungarian) [online]. 2000. University publisher, Budapest. Available: http://www.tankonyvtar.hu/hu/tartalom/tkt/polimertechnika-alapjai/adatok.html.

[3] http://plasticker.de/recybase/docs/27055_1463559873.pdf.

[4] RONKAY, F., CZIGANY, T.: Properties Modifying of Recycled PET with Additives. Proceedings of the Fourth Conference on Mechanical Engineering (BME 2004), Hungary, 170-174, 2004.

[5] General Rheo Training_2015_v1 with Questions [online]. Available: https://www.scribd.com/document/340563607/General-RheoTraining-2015-v1-With-Questions.

[6] TA Instruments Factory Ares G2 Rotational Viscometer Equipment Education Material - Study of Rheology Theory and Applications [online]. Available: http://www.tainstruments.com.

[7] SZUCS, A.: Investigation Polymer Melt Properties High Shear Rate (in Hungarian) [online]. PhD Thesis, University of Miskolc, 2010. Available: http://www.kerpely.uni-miskolc.hu/downloads/docs/cikkek/szucsandras-ertekezes.pdf.

[8] TOTH, G., BATA, A., BELINA, K.: Polycarbonate Melt Shear Viscosity in Wide Range Shear Rate. IOP Conference Series: Materials Science and Engineering, 175(1), paper 012056, 2017. 